\title{
UMA ABORDAGEM HISTÓRICA AO EMPREGO DA DISCIPLINA FÍSICA CORRETIVA E SUAS IMPLICAÇÕES NO ENFRENTAMENTO À VIOLÊNCIA DOMÉSTICA
}

\author{
Dirceu Pereira Siqueira ${ }^{1}$ \\ Luciano Matheus Rahal ${ }^{2}$
}

\begin{abstract}
RESUMO: A disciplina física utilizada pelos pais é fenômeno cultural complexo, enraizado historicamente e causador de violações a direitos da personalidade das crianças. Esta pesquisa resgata as origens da autoridade paterna e aponta os possíveis reflexos desta compreensão na disciplina corretiva dos filhos. Ainda, indica que a concepção da criança como adulto inacabado, o enfraquecimento do poder familiar e o desinteresse dos genitores na educação abnegadora podem resultar em tais práticas. Empregando método hipotético-dedutivo baseado em investigação bibliográfica, com ênfase histórica, os resultados desta pesquisa qualitativa auxiliam na compreensão deste fenômeno e na formulação de políticas visando o enfrentamento desta violência.
\end{abstract}

PALAVRAS - CHAVE: Autoridade parental; Disciplina corretiva; Violência contra criança Violação direitos da personalidade

\section{A HISTORICAL APPROACH TO THE USE OF CORRECTIVE PHYSICAL DISCIPLINE AND ITS IMPLICATIONS ADDRESSING DOMESTIC VIOLENCE}

ABSTRACT: Physical discipline used by parents is a complex cultural phenomenon,
historically rooted, and cause of violations of children's personality rights. This research
resumes the origins of paternal authority and indicates possible reflexes of this understanding
in the corrective discipline. Moreover, it shows that the conception of child as an unfinished
adult, the weakening of family authority and the parents' lack of interest in a self-sacrificing
education can reflect in such practices. Using a hypothetical-deductive method based on

\footnotetext{
${ }^{1}$ Pós-doutor em Direito pela Faculdade de Direito da Universidade de Coimbra (Portugal), Doutor e Mestre em Direito Constitucional pela Instituição Toledo de Ensino -ITE/Bauru, Especialista Lato Sensu em Direito Civil e Processual Civil pelo Centro Universitário de Rio Preto, Pesquisador Bolsista -Modalidade Produtividade em Pesquisa para Doutor -PPD - do Instituto Cesumar de Ciência, Tecnologia e Inovação (ICETI), Professor Permanente do Programa de Mestrado em Direito do Centro Universitário Cesumar (UniCesumar), e nos cursos de graduação em direito da Universidade de Araraquara (UNIARA), do Centro Universitário Unifafibe (UNIFAFIBE) e do Centro Universitário da Fundação Educacional de Barretos (UNIFEB), Professor Convidado do Programa do Programa de Mestrado em "Gestão Estratégica de Empresas -Master Of Science in Administrative Studies (MSAS)" -Disciplina: "Ética e Legislação" University Missouri State -EUA, Consultor Jurídico, Parecerista, Advogado. E-mail: dpsiqueira@uol.com.br

${ }^{2}$ Mestrando no Programa de Pós-Graduação em Ciências Jurídicas da UNICESUMAR (Maringá/PR), Especialista em Direito de Família e Sucessões pela Universidade Anhanguera-Uniderp (2019), em Direito Processual Civil pelo Centro Universitário Internacional - Uninter (2013), em Direito Penal e Processual Penal pela UNIVEL-Cascavel (2009), Graduado em Direito pela Universidade Presbiteriana Mackenzie/SP (2002), Promotor de Justiça da área de família, educação, infância e juventude do Ministério Público do Estado do Paraná desde junho de 2005. E-mail: rahalluciano@hotmail.com
} 
bibliographic research with historical emphasis, the results of this qualitative research helps to understand this phenomenon and formulate policies coping this violence.

KEYWORDS: Parental authority; Corrective discipline; Violence against children; Personality rights violation.

\section{INTRODUÇÃO}

A violência doméstica contra crianças e adolescentes, apesar dos inegáveis avanços legislativos das últimas décadas, teimosamente subsiste como fenômeno mundial, com impactos imensuráveis e, em muitos casos, irreversíveis sobre este público especialmente vulnerável.

Esta modalidade de violência atinge indiscriminadamente todos os lares, das mais diversas raças, etnias, nacionalidades, religiões, condições econômicas e escolaridade, portanto, neste sentido, atinge democraticamente os mais diversos núcleos familiares.

Neste contexto de violência familiar, a prática multicausal do emprego da correção física imoderada contra filhos menores possui profundas raízes históricas, as quais, ainda hoje, impactam a disciplina parental.

Por meio de abordagem histórica, constatou-se que enquanto o homem, e, mais tardiamente, a mulher, passaram a ser compreendidos como seres humanos cuja dignidade passou a ser reconhecida mais claramente a partir da era pós-cristã, a criança somente tornouse destinatária de uma tutela diferenciada da sociedade e, por conseguinte, do legislador, a partir dos séculos XIX e XX.

Neste contexto de déficit protetivo que remonta aos primórdios da civilização ocidental, os infantes sempre foram estigmatizados como "peso" social e familiar, fontes de constantes despesas, adultos inacabados cuja dignidade e respeito enquanto cidadãos viria somente com o matrimônio, o trabalho ou o chamado sacerdotal.

Este ambiente incentivava o "abortamento" da infância e o despertamento precoce da idade adulta, subtraindo deste grupo vulnerável o "período de ouro" para a maturação da personalidade e caráter, que hoje reconhecemos como adolescência. As violações aos direitos mínimos vinculados à personalidade infantojuvenil, portanto, eram sistematicamente ignoradas.

Desta forma, uma das raízes históricas desta modalidade de violência doméstica, objeto desta pesquisa, estaria na exigência social atribuída ao pai (pater familiae) em formatar 
moralmente este ser incompleto no âmbito de sua mais ampla autoridade familiar, tendo à sua disposição todos os meios necessários para este mister, inclusive os meios corretivos físicos e psicológicos.

Outra possível causa deste fenômeno pode ser identificada no próprio esfacelamento da autoridade parental, num contexto de pós-modernidade em que as relações pessoais, e, por conseguinte, também as relações familiares, encontram-se em processo de "liquefação".

Em razão da fragilização desta relação de poder e o próprio descomprometimento com a educação construtiva dos filhos, já na primeira infância, percebe-se que os pais podem estar utilizando-se deste recurso corretivo extremo para "compensar" estas deficiências, gerando resultados desastrosos na formação psíquica das crianças.

Com o emprego de método hipotético-dedutivo baseado fundamentalmente em investigação bibliográfica, notadamente fontes históricas, de natureza qualitativa, o presente artigo pretende apresentar estas e outras possíveis causas estruturais para a persistente prática da violência intrafamiliar contra crianças, enquanto fenômeno brasileiro e mundial.

Ao final, conclui-se que a compreensão destes complexos fatores merece a devida atenção na construção de políticas públicas e abordagens voltadas a este público especialmente vulnerável e violentado, igualmente detentor de direitos personalíssimos que carece de uma eficiente tutela familiar, estatal e comunitária.

\section{O PODER FAMILIAR E O EMPREGO DA DISCIPLINA CORRETIVA AO LONGO DA HISTÓRIA}

Para uma genuína compreensão da persistente prática da violência familiar contra o público infantojuvenil no contexto brasileiro e apontar possíveis horizontes visando seu enfrentamento, revela-se oportuno o estudo do panorama familiar ocidental sob a ótica de sua herança religiosa, jurídica e cultural, desde seus primórdios.

Lastreando-se nas reflexões do pensador inglês do século XVIII, Edmund Burke, ao comentar o ambiente político-cultural britânico de sua época, pós-revolução francesa, compreende-se que todas as reformas estruturais que se pretenda realizar enquanto nação devem respeitar "o princípio de referência ao passado" e serem construídas sobre estes precedentes (BURKE, 2019, p.55). 
Neste sentido, portanto, nos limites inerentes a esta modalidade específica de pesquisa, este primeiro capítulo propõe-se expor parte desta complexa e controversa herança histórica que moldou tanto o conceito de autoridade parental, o emprego da disciplina física corretiva, quanto a própria concepção do "ser criança", com vistas a fornecer subsídios que possam pavimentar outros caminhos para esta reforma estrutural no trato infantojuvenil no ambiente familiar.

\subsection{NA CULTURA OCIDENTAL}

Fustel de Coulanges (2020), em sua clássica obra La Cité Antique (A Cidade Antiga), a partir da análise da sociedade Grega e Romana antiga à luz de textos históricos e poéticos da época, permite a compreensão da influência da religião doméstica (fogo sagrado) na construção e manutenção das entidades familiares, e, neste contexto, o papel fundante do pai como o primeiro junto ao lar, como aquele que alumia e conserva a família, seu verdadeiro pontífice.

Além da absoluta ascendência sobre a esposa, também "os filhos continuam unidos ao lar paterno, e, por consequência, submetidos à sua autoridade; enquanto ele viver, são considerados menores" (COULANGES, 2020, p.85).

Neste sentido, Coulanges compreendia a família antiga como:

[...] um pequeno corpo organizado, uma pequena sociedade, que tinha seu chefe e seu governo (...) Nada, em nossa sociedade moderna, pode dar-nos ideia desse poder paternal. Nesses tempos antigos, o pai não é somente o homem forte que protege, e que tem também poder para se fazer obedecer: ele é sacerdote, é o herdeiro do lar, e continuador dos antepassados, o tronco dos descendentes, o depositário dos ritos misteriosos do culto e das fórmulas secretas da oração. Toda a religião reside nele (COULANGES, 2020, p.85).

Desta forma, ao pater familiae eram conferidos direitos absolutos sobre sua esposa, filhos e escravos, como o direito de reconhecer ou rejeitar a criança no ato do nascimento, direito de repudiar a mulher em caso de esterilidade, direito de casar a filha, direito de propriedade sobre os bens dos filhos e esposa ${ }^{3}$, direito de venda dos filhos e direito exclusivo de demandar em Juízo:

Se a justiça, para o filho e a mulher, não estava na cidade, é porque ela estava no lar. Seu juiz era o chefe da família, sentado como que em um tribunal, em virtude de sua

\footnotetext{
${ }^{3}$ Uma vez que o conceito de propriedade era sempre familiar. (COULANGES, 2020).
} 
autoridade conjugal ou paterna, em nome da família e sob os olhos das divindades domésticas (COULANGES, 2020, p. 90).

Este direito de justiça atribuído ao chefe da família era absoluto e irrecorrível, o pai poderia condenar à morte e nenhuma autoridade tinha o direito de modificar sua sentença. No seio da família, ele era o único e incontestável magistrado: o magistrado doméstico.

O mesmo autor fez referência a relato de Valério Máximo, escritor romano do século I, o qual citou "certo Atílio, que matou a filha culpada de impudicícia, e todo mundo conhece aquele pai que matou o filho, cúmplice de Catilina" (MÁXIMO, IV, 1, 3-6 apud COULANGES, 2020, p. 90).

Para Coulanges (2020), exemplos como este são numerosos na história romana, eis que o pai de família se submetia apenas ao julgamento da cidade: a mulher e o filho não podiam encontrar outro juiz além dele.

$\mathrm{Na}$ família romana antiga, a fonte deste poder paterno, entretanto, não se encontrava respaldado no direito do mais forte, exercido de forma arbitrária, ou no Estado, porém fundamentado "nas crenças que estavam no fundo das almas, e encontravam seus limites nessas mesmas crenças" (COULANGES, 2020, p. 90), em outras palavras, tanto a origem como os limites deste poder eram exercidos pela tradição, mitos e crenças.

Nesta mesma linha, a despeito da polêmica acerca da origem, codificação e autenticidade da Lei das XII Tábuas, conforme bem pontua o professor José Carlos Moreira Alves, inegável que este corpo legislativo refletiu o espírito de sua época, com o objetivo de "refrear o arbítrio dos magistrados patrícios contra a plebe" (ALVES, 2018, p.53).

Segundo Moreira Alves (2018), apesar de não ter chegado aos nossos dias o texto completo da Lei das XII Tábuas, dela conhecemos alguns fragmentos que foram transcritos por autores literários e jurisconsultos, dentre os quais a "Tábua IV", regulamentadora do jure pátrio:

Tábua IV (De jure patrio)

1.É permitido ao pai matar o filho que nasceu disforme, mediante o julgamento de cinco vizinhos.

2. O pai terá sobre os filhos nascidos de casamento legítimo o direito de vida e de morte e o poder de vendê-los.

3. Se o pai vendeu o filho 3 vezes, que este filho não recaia mais sob o poder paterno. (MEIRA, 1972, p.169). 
Com a lei das XII Tábuas, codificou-se, portanto, o poder de vida e morte do pai para com a pessoa dos filhos que ainda se encontrassem sub manu, ou seja, mesmo os filii homens adultos permaneciam debaixo da autoridade do pater enquanto este vivesse, e não podiam adquirir os direitos de pater familias até à sua morte. Legalmente, toda a propriedade que os filii adquirissem era em nome do pater, e este detinha a autoridade última sobre seus destinos.

Esta extensão quase absoluta do poder familiar prevaleceu durante todo o período régio Romano, sofreu moderações nos períodos republicano e do principado e, somente no segundo século da era cristã, foi reduzido ao âmbito do direito de correção. Esta evolução civilizatória encontra-se muito bem consubstanciada na máxima do jurisconsulto Marciano, inspirada na filosofia estoica: Pátria potestas in pietate debet, nec atrocitate consistere 4 (NORONHA, 2017).

Ou seja, principalmente a partir do advento do cristianismo e a centralidade conferida à criança na nova aliança espiritual introduzida por Jesus de Nazaré ${ }^{5}$, a autoridade patriarcal e o magistério doméstico romano passaram a sofrer significativas restrições no mundo ocidental. Entretanto, como será exposto, esta influência ainda persistirá por séculos, impactando a cultura e sistemas legislativos até os dias atuais.

Esta lenta evolução pós-cristã do conceito de criança foi brilhantemente captada pelo sociólogo francês Phillip Ariés (1986) em sua clássica obra "História Social da Criança e da Família”. Até por volta do século XII, Ariés constatou que a arte medieval desconhecia a infância ou não tentava representá-la, concluindo que não havia lugar para a infância naquele mundo, eis que "a infância era um período de transição, logo ultrapassado, e cuja lembrança também era logo perdida" (ARIES, 1986, p.52).

Somente a partir do século XII surgiram ilustrações de crianças um pouco mais próximas do sentimento moderno, porém, até o século XIV, esta representação artística era essencialmente limitada à figura do menino Jesus. Os retratos isolados de crianças por artistas viriam somente a avolumar-se após o século XVII, indicando um incipiente protagonismo infantil em uma sociedade ainda profundamente centralizada na figura paterna (ARIES, 1986).

No mesmo sentido, a indiferença infantil que prevalecia até o século XIII era também manifestada no vestuário, na medida que as crianças eram vestidas como os outros

\footnotetext{
4 A autoridade dos pais deve se manifestar com afeto, não com severidade excessiva (tradução nossa).

5 Evangelho de Marcos 10:14. "Jesus, porém, vendo isto, indignou-se e disse-lhes: Deixai vir a mim os pequeninos, não os embaraceis, porque dos tais é o reino de Deus” (ALMEIDA, 2008, p.1664).
} 
adultos da época, condição esta que somente passou a ser parcialmente superada com a utilização de trajes especificamente infantis, por volta do século XVIII, principalmente nas abastadas famílias burguesas (ARIES, 1986).

Ainda, a inocência infantil, hoje conceito bastante difundido e uma das leis não escritas de nossa moral contemporânea, era sentimento totalmente estranho à antiga sociedade medieval. Naquele contexto, a "prática familiar de associar as crianças às brincadeiras sexuais dos adultos fazia parte do costume da época e não chocava o senso comum”, segundo Aries (1986, p.128). Ou seja, do despudor dos séculos iniciais do segundo milênio até o clima moral contemporâneo, houve uma lenta evolução dos costumes, ainda em constante mutação.

No que se refere à disciplina familiar, objeto principal desta pesquisa, o citado professor esclareceu que os séculos XIV e XVII nos permitiram identificar dois aspectos fulcrais que permeariam a educação de crianças por séculos, com reflexos até os dias atuais: a disciplina humilhante e a dilatação da idade escolar (ARIES, 1986).

A primeira, simbolizada pelo chicote, entendia o castigo corporal como fundamental no processo educacional escolar e familiar e refletia uma concepção autoritária e hierarquizada (absolutista) da sociedade na época. No topo desta hierarquia encontrava-se a figura do pai (no lar) e do professor (nas instituições educacionais).

A segunda implicava a possibilidade desta correção, inicialmente destinada às crianças, estender-se durante toda a idade escolar, que, em muitos casos, ultrapassava os 20 anos, atingindo inclusive jovens adultos.

O fundamento destas práticas era a concepção existente de "fraqueza infantil", que demandaria uma intervenção enérgica e humilhante do disciplinador visando a salvação da alma das crianças pelas quais estes adultos eram responsáveis perante Deus, pensamento este fortemente influenciado pela tradição jesuítica que, em solo brasileiro, levou à replicação deste modelo perante os nativos indígenas e sistema educacional como um todo (PAIVA, 2015).

Avançando um pouco mais em termos históricos, o Código Napoleônico (Code Civil), considerado por muitos como "o mais importante código do século XIX, influenciando vários outros" (NETO, 2013, p.68), quando publicado em 1804, imediatamente passou a vigorar em vários territórios europeus sob o domínio francês. 
Com efeito, o imperialismo napoleônico que se seguiu à publicação do Código garantiu a propagação coerciva e cultural deste Code, inclusive em território português ${ }^{6}$ e, além do Atlântico, nos países latino-americanos. Nas palavras do professor Eugênio Facchini Neto, o "modelo do code civil atravessou o oceano e encontrou terreno fértil na América Latina, que nesse período estava em processo de independência e em busca de novos modelos para romper o passado colonialista" (2013, p.78/79).

O Código Francês de 1804, como obra cultural, inegavelmente refletiu uma longa evolução histórica, portanto, apesar de importantes rupturas com o ancien régime, produto da revolução francesa deflagrada anos antes, representava "uma grande continuidade com um passado que se perde nas brumas da história” (NETO, 2013, p.60).

Dentre os vários institutos regulamentados nesta legislação codificada, o Poder Paternal (Puissance Paternelle) merece o devido destaque eis que regulamentou detalhadamente, de forma até então inédita, a prática da correção paternal.

Segundo Cavichioli (2019), "com o Código Civil de 1804, o interesse da criança era identificado com a obediência ao pai, tutelada e protegida pelo Estado por meio do procedimento de correção paternal" (CAVICHIOLI, 2019, p.88).

Em poucas palavras, a correção paternal correspondia a um mecanismo de educação e disciplina dos filhos aplicado pelo Estado, a partir de mero requerimento do pai, previsto nos artigos 375 a 383 do Código Civil francês de 1804.

Neste âmbito de absoluta liberdade e ausência de limitação estatal ao exerício do ius corriendi paterno, este poderia pedir a prisão de seu filho por grave descontentamento, ao passo que ao Poder Judiciário seria vedado o exame da veracidade dos motivos, "como se o âmbito familiar fosse, verdadeiramente, privado da governança pública e inteiramente sujeito ao governo paterno" (CAVICHIOLI, 2019, p.81).

Assim, textualmente:

Art. 376. Se a criança não tiver completado dezesseis anos, o pai pode fazer com que ela seja confinada por um período que não deve exceder um mês; e, para esse efeito, o presidente do tribunal do círculo será obrigado, a seu pedido, a proferir uma ordem de prisão.

A partir dos 16 anos, até a maioridade ou emancipação, este período de confinamento poderia estender-se até seis meses (art.377).

\footnotetext{
${ }^{6}$ Código Civil Português (Código Seabra), publicado em $1^{\circ}$ de julho 1867.
} 
Em qualquer dos casos, entretanto, era dispensada "qualquer formalidade escrita ou judicial, exceto a própria ordem de prisão, na qual não serão indicados os respectivos motivos" (art. 378). Ao pai caberia tão somente o compromisso de custear todas as despesas e fornecer o sustento adequado ao fiho detido, podendo, ainda, abreviar a duração do confinamento (art. 379).

$\mathrm{Na}$ correção via autoridade, como visto, a ordem de encarceramento do filho dependia da concomitância de algumas poucas condições as quais, caso preenchidas, independentemente da exposição dos motivos, não poderia ser rejeitada pelo Poder Judiciário.

Apesar de ter recebido duras críticas por parte de juristas por tratar-se dos poderes mais extensos e rigorosos conferidos ao pai entre todos os países europeus segundo Bernard Schnapper (1991, apud CAVICHIOLI, 2019), inegavelmente refletia a moral vigente de sua época, que não se abalou mesmo ante a violenta tentativa de ruptura social deflagrada pela Revolução Francesa anos antes.

\subsection{EM SOLO BRASILEIRO}

Até o século XIX, o território brasileiro era regulado pelas sucessivas ordenações portuguesas e pelo direito canônico, os quais revelavam flagrante despreocupação com a integridade física/psíquica das crianças no ambiente familiar, notadamente quando fruto de disciplina paterna. A responsabilidade corretiva dos filhos era essencialmente uma atribuição do genitor e a defesa dos direitos da personalidade das crianças era demanda de baixa relevância social.

Tanto que a primeira legislação brasileira que conferiu algum tipo de tutela ao público infantil foi somente a Lei do Ventre Livre ${ }^{7}$, ao libertar as crianças nascidas de negros cativos e proibir a separação dos cônjuges e dos filhos menores de 12 anos.

Infelizmente este quadro poucas alterações sofreu com a codificação civilista de $1916^{8}$, profundamente inspirada na família patriarcal, na medida que os parcos dispositivos que tratavam da condição dos filhos revelavam um maior interesse com os reflexos patrimoniais da filiação (art.380 e 385) ou com a regulamentação da guarda, principalmente

\footnotetext{
${ }^{7}$ Lei Federal n. 2040 de 28 de setembro de 1871.

Art. $1^{\circ}$. Os filhos de mulher escrava que nascerem no Imperio desde a data desta lei, serão considerados de condição livre. [...]

$\S 5^{\circ}$ No caso de alienação da mulher escrava, seus filhos livres, menores de 12 annos, a acompanharão, ficando o novo senhor da mesma escrava subrogado nos direitos e obrigações do antecessor.

${ }^{8}$ Lei Federal no 3.071 , de $1^{\circ}$ de janeiro de 1916.
} 
decorrente do desquite dos genitores, cujo principal critério balizador era a "culpa" dos cônjuges, e não o secundário interesse das crianças (arts.325 a 329).

Entretanto, há de ser reconhecido que pela primeira vez introduziu-se expressamente como causa destituidora do pátrio poder o castigo imoderado dos filhos ${ }^{9}$, refletindo uma crescente preocupação do legislador com os excessos na correção dos filhos e suas terríveis consequências, muito embora o critério de moderação fosse absolutamente subjetivo e sujeito à interpretação judicial, profundamente influenciada pela moral social predominante (moral religiosa católica).

$\mathrm{Na}$ década seguinte, houve o surgimento do grande marco legal brasileiro na tutela dos direitos das crianças e adolescentes, qual seja, o Código Melo Matos (Decreto n. 17.943A, de 12-10-1927), assim chamado em homenagem a seu autor, o jurista baiano José Cândido de Albuquerque Mello Mattos, posteriormente nomeado o primeiro juiz de menores do Brasil.

Em seu artigo 26, inciso VII, o Código considerava "expostos" os menores de 18 anos "que, devido á crueldade, abuso de autoridade, negligencia ou exploração dos paes, tutor ou encarregado de sua guarda, sejam: a) victimas de máos tratos physicos habituaes ou castigos immoderados”. Ainda, na linha do Código Beviláqua (1916), consolidou como hipótese de perda do pátrio poder o "pai ou mãe que castigar imoderadamente o filho"10.

Mesmo tendo previsto uma série de "medidas de assistência e proteção"11 ao menor de 18 anos, seu público preferencial eram os então chamados "expostos, abandonados e delinquentes". Tanto que o parágrafo único do artigo 61 definia o menor vadio ou mendigo habitual como aquele apreendido em estado de vadiagem ou mendicidade mais de duas vezes, sujeito à internação em "escolas de preservação", revelando a nítida compreensão das crianças e adolescentes como objetos de intervenção estatal e não como sujeitos de direito, plenos e autônomos.

Ainda, introduziu-se ineditamente em território brasileiro os Tribunais de Menores, refletindo a forte influência do correcionalismo e positivismo criminológico (SPOSATO, 2011, p.144) no direito pátrio, visando a reforma moral do delinquente, "que seria aquele cuja vontade é defeituosa e que poderia ser submetido a um processo de cura" (ZAPATER, 2019, p.41).

\footnotetext{
${ }^{9}$ Art. 395. Perderá por ato judicial o pátrio poder o pai, ou mãe:

I - que castigar imoderadamente o filho;

${ }^{10}$ Art. 32, inciso III.

11 Art. $1^{\circ}$. O menor, de um ou outro sexo, abandonado ou delinquente, que tiver menos de 18 annos de idade, será submettido pela autoridade competente ás medidas de assistencia e protecção contidas neste Codigo.
}

Revista de Direito de Família e Sucessão | e-ISSN: 2526-0227 | Encontro Virtual | v. 7 | n. 2 | p. $23-44$ | Jul/Dez. 2021. 
Percebe-se, portanto, que o juiz de menores exercia uma atribuição paternal, corretiva e educativa de natureza subsidiária, é dizer, na insuficiência da disciplina parental, o Estado estaria dotado (em tese) de aparato de vigilância suficiente para suprir esta carência através de um "logar conveniente""12, dentre estes: hospital, asilo, instituto de educação, oficina escola de preservação ou de reforma.

A "atualização" deste diploma normativo viria somente mais de 50 anos depois, com o Código de Menores de 1979 (Lei Federal n. 6.667, de 10 de outubro de 1979). Entretanto, a despeito do tempo e evolução mundial no trato infantojuvenil, a doutrina do "direito do menor", introduzida pelo Código Melo Matos, se consolidaria no Código de Menores desta vez sob a nomenclatura de "menor em situação irregular". Pode-se compreender referida "inovação" legislativa, portanto, como uma pseudoevolução nos direitos deste público especialmente vulnerável.

Criado em pleno período militar, este Código já pontuava expressamente em seu artigo $1^{\circ}$ o foco primordial de atenção: assistência, proteção e vigilância a menores. Neste escopo, a "questão dos menores" era tratada como problema de segurança nacional, sendo estes divididos entre aqueles cuja situação era irregular ou regular, sendo que, com relação a estes últimos, "o Estado não se ocupa, pois somente as crianças em situação irregular serão legalmente definidas e estarão sob a vigilância do Estado" (ZAPATER, 2019, p.53).

Neste aspecto, o Código de Menores considerava em situação irregular aquelas crianças e adolescentes privados de condições essenciais, vítimas de maus tratos e castigos imoderados, em perigo moral, privados de representação ou assistência legal, com desvio de conduta ou autores de infração penal, por ação, omissão, impossibilidade ou grave inaptidão familiar (art. $\left.2^{\circ}\right)$.

Constata-se, a exemplo do Código Melo Matos, a natureza suplementar da intervenção estatal com vistas ao "resgate" da criança ou adolescente ineficientemente educado e disciplinado pelos pais ou responsáveis. A despeito da consolidação do parâmetro da vedação de "castigos imoderados" por parte dos pais, o legislador claramente omitiu-se

\footnotetext{
${ }^{12}$ Art. 55. A autoridade, a quem incumbir a assistencia e pprotecção aos menores, ordenará a apprehensão daqulles de que houver noticia, ou the forem presentes, como abandonados os depositará em logar conveniente, o providenciará sobre sua guarda, educação e vigilancia, podendo, conforme, a idade, instrucção, profissão, saude, abandono ou perversão do menor e a situação social, moral e economica dos paes ou tutor, ou pessoa encarregada de sua guarda, adoptar uma das seguintes decisões.
} 
quanto à situação dos menores "regulares", quais sejam, aqueles dotados de pai e mãe, e educados de acordo com a moral vigente à época.

Em outras palavras, até a Constituição Brasileira de 1988 e, mais claramente, até o Estatuto da Criança e do Adolescente de 1990, manteve-se, em essência, uma ampla liberdade para o exercício do poder disciplinador do pater familae.

Dos pais, mais especificamente da figura paterna, o Estado esperava uma educação firme, assertiva, moralista e expurgadora, tolerando implicitamente práticas corretivas que viessem corrigir condutas desviantes dos filhos menores, desde tenra idade.

Caso os genitores falhassem neste mister e produzissem filhos "irregulares", o Estado paternal, portanto, personificado na Fundação Nacional do Bem-Estar do Menor, no exercício de sua vigilância seletiva, encarregava-se de suprir esta deficiência com todo seu aparato próprio (entidades públicas - art. $9^{\circ}$ ) ou terceirizado (entidades particulares - art. 10) simbolizado pelas unidades de internação (FEBEM em âmbito estadual), reformatórios, abrigos, dentre outros similares.

Caberiam aos pais, portanto, evitar este constrangimento e lançarem mão de todos os meios disponíveis para o resgate destas pequenas almas perdidas com condutas desviantes (art.41), sob pena da intervenção salvífica estatal por meio de internação em "estabelecimento adequado", de caráter educacional, ocupacional, psicopedagógico, hospitalar, psiquiátrico, dentre outras medidas (art.14).

\section{A MUDANÇA DE PARADIGMA NUM CONTEXTO CULTURAL AINDA MARCADO PELA VIOLÊNCIA DOMÉSTICA}

A violência infantil, enquanto grave problema social, somente teve significativo reconhecimento legislativo a partir da segunda metade do século XX, simbolizado em dois marcos normativos que trouxeram novos paradigmas a esta antiga problemática: a Convenção Internacional sobre os Direitos da Criança e do Adolescente de 1989, no plano internacional, e a Constituição Federal de 1988, no âmbito doméstico brasileiro.

Neste sentido, referida carta internacional da ONU ampliou o conceito de violência contra criança, em seu artigo 19, passando a exigir dos Estados Partes que adotassem "todas as medidas apropriadas para proteger a criança contra todas as formas de violência física ou mental, ofensas ou abusos, negligência ou tratamento displicente, maus-tratos ou exploração, inclusive abuso sexual [...]". 
E mais, num movimento internacional pioneiro, tais violências deveriam ser combatidas pelos Estados não somente no plano institucional ou comunitário, mas "enquanto a criança estiver sob a custódia dos pais, do tutor legal ou de qualquer outra pessoa responsável por ela".

Em outras palavras, a ONU invadiu a até então relativamente intocada seara familiar, superando a resistência inicial de muitos países de tradições religiosas e culturais diversas, e alargou o conceito de violência infantil para além das visíveis sevícias físicas (castigos imoderados), abarcando igualmente as veladas agressões psicológicas bem como o comportamento negativo dos genitores (negligência), cujos danos, inicialmente pouco perceptíveis, teriam a potencialidade de acarretar sequelas ainda mais significativas que a própria agressão física.

No plano constitucional brasileiro houve a inédita introdução de dispositivo tutelar específico voltado para a população infanto juvenil, sedimentando um microssistema protetivo até então esparso em legislações infraconstitucionais.

Neste contexto, o artigo 227 da Constituição Federal instituiu a dignidade humana também como um pressuposto do "ser criança", impondo à família, à sociedade e ao Estado a obrigação de assegurar um mínimo existencial de direitos a este público especialmente vulnerável.

Desta forma, o “direito à vida, à saúde, à alimentação, à educação, ao lazer, à profissionalização, à cultura, à dignidade, ao respeito, à liberdade e à convivência familiar e comunitária num ambiente a salvo de toda forma de negligência, discriminação, exploração, violência, crueldade e opressão", nesta nova dinâmica constitucional, viabilizaram a emancipação das crianças e adolescentes como sujeitos de direitos, em flagrante oposição aos conceitos de "menor exposto" (Código Melo Mattos) ou de "menor em situação irregular" (Código de Menores).

Em outras palavras, o artigo 227 da Carta Constitucional redefiniu ontologicamente o próprio conceito de criança ao assegurar a este público um manto mínimo de garantias, uma tutela básica da personalidade infantojuvenil enquanto direito inalienável, na tentativa de propiciar um espaço seguro para o desenvolvimento de suas potencialidades e virtudes enquanto cidadãos plenos, não mais embrionários.

Neste plano, a Constituição Cidadã, sem qualquer pretensão conceitual, equiparou a violência infantil à negligência, à discriminação, à exploração, à violência, à crueldade e à 
opressão, elencando, numa análise contextual do dispositivo, todas estas práticas como geradoras de violência num sentido amplo, inclusive a violência intrafamiliar.

Estes novos ares legislativos, impulsionados, como visto, tanto pela comunidade internacional (ONU) como pelo constituinte de 1988, encontraram forte eco normativo no âmbito do processo de redemocratização brasileiro por meio da lei n. 8.069/90 (Estatuto da Criança e do Adolescente), a qual, já em seu artigo $3^{\circ}$, reconheceu expressamente "que a criança e o adolescente gozam de todos os direitos fundamentais inerentes à pessoa humana".

Sob este novo marco legislativo, portanto, a dignidade da criança foi formalmente reconhecida como expressão de seu próprio direito à personalidade, enquanto ser em formação.

Nas palavras de Zapater:

\begin{abstract}
"Essa nova concepção acarreta transformações socioculturais em vários aspectos, o que inclui o Direito: a modificação na maneira de se pensar crianças e adolescentes irá gerar novas premissas, segundo as quais as relações sociais integradas por estes sujeitos estarão pautadas a partir de então, o que reverberará nas normas jurídicas produzidas neste contexto $(2019$, p.71)."
\end{abstract}

Entretanto, passados mais de 30 anos da publicação deste marco normativo, celebrando a criança como sujeito pleno de direitos, a violência infantojuvenil ainda persiste enquanto prática cultural.

O Disque Direitos Humanos (Disque 100), ferramenta telefônica disponibilizada pelo Governo Federal para receber, analisar e encaminhar denúncias de violações de direitos humanos, dentre estas os casos de violência contra crianças e adolescentes, contabilizou "em 2019 um total de 86.837 denúncias de violações de direitos humanos contra crianças e adolescentes, 14\% a mais do que no ano de 2018" (ONDH, 2019, p.18).

Este relatório destacou que as principais violações sofridas por esse grupo foram, em escalada decrescente: negligência (38\%), violência psicológica (22\%), física (21\%), sexual (11\%), institucional (3\%), e exploração do trabalho (3\%). Outros dados merecedores de atenção para o objeto deste estudo foram os locais onde estas violências ocorreram bem como o sujeito ativo e passivo da ação violenta: $52 \%$ ocorreram na casa da vítima, sendo a violência praticada em 58\% das vezes pela mãe ou pai, tendo como alvo majoritário meninas (55\%).

No plano internacional, as estatísticas não revelam-se distintas. Em detalhado relatório elaborado em 2002 pela Organização Mundial de Saúde (OMS), baseado em 
literatura e pesquisas produzidas em diversos países, concluiu-se que a "violência infantil é um fenômeno mundial" (KRUG, 2002, p.81).

As consequências desta violência, inclusive quando fruto do exercício da disciplina, podem ser desastrosas, com prejudiciais reflexos cognitivos, comportamentais, psicológicos e emocionais às crianças e adolescentes, com potencial de tornarem-se permanentes (SEGE; SIEGEL, 2018).

Neste desafiador cenário, ao abordar este aparente tensionamento entre a violência infantil, com profundas raízes históricas, e o exercício da disciplina no âmbito do poder familiar, revela-se prudente superar a análise compartimentada da vítima e do agressor para debruçar-se sobre o cerne desta complexa problemática (KRUG, 2002).

\section{A VIOLÊNCIA NO EMPREGO DA DISCIPLINA}

A disciplina, enquanto prática pedagógica, é indissociável do processo educativo, tanto que Imannuel Kant, em escrito já da segunda metade do século XVIII intitulado "Sobre a Pedagogia" (1999) conceituou a educação como o cuidado de sua infância, da qual faz parte a disciplina e a instrução com a formação. Neste sentido, Kant classificou o homem como infante, educando e discípulo, entendendo como conceitos indissociáveis. Ressaltou, ainda, que a falta de disciplina é "um mal pior que falta de cultura, pois esta pode ser remediada mais tarde, ao passo que não se pode abolir o estado selvagem e corrigir um defeito de disciplina." (KANT, 1999, p.16).

A disciplina infantil, portanto, neste aspecto, carrega toda a responsabilidade de dar o primeiro passo em direção ao objetivo final do ser humano, na medida que seu papel é de afastar o ser em formação de sua menoridade, tarefa esta primariamente conferida aos pais a quem culturalmente é atribuída a educação da prole.

Neste panorama disciplinar, apesar da multiplicidade e complexidade das causas geradoras da violência em geral contra a criança no âmbito doméstico (MARTINS, 2010), inegável a herança histórico-cultural do papel atribuído aos pais no exercício da disciplina corretiva, inclusive com o emprego de castigos físicos (RANGEL, 2013).

Neste particular contexto, Maria Aparecida Alkimin (2016) destacou dois fatores que concorreriam para a prática da violência doméstica contra a crianças e adolescentes: o império da relação domínio-poder e a vulnerabilidade da criança. Ambos muito bem presentes, em 
graus variados, em todos os períodos históricos, implícitos na autoridade paterna e no dever de cuidado e educação.

Esta relação de poder, como visto, possui profundas e amplas raízes religiosas, políticas, culturais e econômicas, elementos estes intrinsicamente ligados a uma cultura patriarcal ancorada na submissão não somente da mulher, como também, com ainda maior intensidade, na prole criança. Pode-se afirmar que a própria sobrevivência desta relação de poder historicamente dependeu, em grande medida, da violência como fonte legitimadora do poder parental corretivo.

Esta leitura da autoridade ancorada na força recebeu severas críticas por parte de Hannah Arendt (2001), por compreender o poder/autoridade e a violência não como complementares, mas mutuamente excludentes:

\begin{abstract}
A autoridade, relacionando-se ao mais enganoso destes fenômenos e, portanto, sendo um termo do qual se abusa com frequência, pode ser investida em pessoas - há algo como a autoridade pessoal, por exemplo, na relação entre a criança e seus pais, entre aluno e professor; [...] A sua insígnia é o reconhecimento inquestionável por parte daqueles a quem se pede que obedeçam; nem a coerção nem a coação são necessárias. (Um pai pode perder a autoridade tanto batendo em seu filho quanto discutindo com ele, ou seja, tanto comportando-se em relação a ele como um tirano quanto tratando-o como um igual). Conservar a autoridade requer respeito pela pessoa ou pelo cargo. Um maior inimigo da autoridade é, portanto, o desprezo, e o mais seguro meio para miná-la é a risada (ARENDT, 2001, p.37, destaque nosso).
\end{abstract}

Celso Lafer, prefaciando referida obra, argumentou que Arendt compreende o poder e violência como opostos, eis que a afirmação de um significa a ausência do outro, de modo que é a "desintegração do poder que enseja a violência, pois quando os comandos não são mais generalizadamente acatados, por falta do consenso e da opinião favorável, implícita ou explícita, de muitos, os meios violentos não têm utilidade" (ARENDT, 2001, p.8).

É dizer, para esta pensadora, a violência (incluindo a doméstica) ao invés de legitimadora da autoridade revela justamente o contrário, na medida que a necessidade de uma ação violenta por parte do detentor do poder (os pais) para com os subordinados (filhos) é indício da própria fragilidade deste poder.

Analogicamente, pais que lançam mão de castigos físicos imoderados, ou mesmo moderados reiterados, como método para legitimar sua autoridade sobre a pessoa dos filhos, revelam um verdadeiro esvaziamento do poder parental.

Pais que empregam violência física ou psicológica contra a pessoa dos filhos revelam que o fundamento da autoridade é internamente débil porquanto a obediência, quando 
presente, não é produto do respeito pelo detentor do poder, mas de "coerção", característica da figura do "tirano" (ARENDT, 2001).

Neste raciocínio, considerando que o fundamento do emprego da violência como método corretivo dos filhos é, paradoxalmente, a própria perda da legitimidade do detentor do poder (pais), iniciativas como a lei federal n. 13.010/2014 ("Lei da Palmada"), que, ao introduzir o artigo 18-B na lei n. 8.069/90 (ECA), veda a utilização de castigo físico ou tratamento cruel ou degradante como formas de correção, disciplina e educação, possuem eficácia bastante limitada e simbólica.

A abordagem a esta milenar problemática, qual seja, o emprego de violência contra filhos menores como método pedagógico, portanto, demandaria da sociedade civil e poder público uma ressignificação da própria autoridade parental, não para diminuí-la, mas para contextualizá-la num ambiente de diluição da autoridade e das relações familiares.

Neste sentido, segundo Zygmunt Baumann (2001), na sociedade pós-moderna, os poderes, dentre estes podemos seguramente incluir o outrora incontestável pátrio poder, assim como os padrões de dependência e interação, encontram-se em acelerado estado de liquefação (2001, p.192).

Neste desafiador contexto "liquefeito", as instâncias públicas e privadas, inclusive espaços religiosos, poderiam dedicar seus esforços no empoderamento da autoridade parental como referência de ética, respeito, integridade, sacrifício, compromisso, tolerância e amor para com a família e sociedade.

O dilema que se escancara no presente horizonte, quando se aborda a disciplina de filhos, aparentemente não consiste, portanto, na imposição de regras penalizadoras aos pais zelosos que castigarem pontualmente seus filhos de forma moderada num contexto pedagógico consciente, mas no resgate da autoridade parental em sua essência, que é sacrificial.

Na verdade, a omissão parental (negligência), ou, o não agir, como visto (ONDH, 2019), tem se revelado estatisticamente muito mais presente e danoso em solo brasileiro, na medida que reflete a irresponsabilidade e indiferença com a prole, abortando, ab initio, qualquer projeto educacional familiar consistente.

Em certa medida, o emprego de castigos físicos igualmente reflete esta negligência na medida que pode revelar um agir tardio e desesperado, fruto de uma omissão prévia 
persistente: um adolescente refratário pode ser resultado da indiferença dos pais na primeira infância do filho.

De qualquer forma, assegurar às crianças e adolescentes as facilidades e oportunidades "a fim de lhes facultar o desenvolvimento físico, mental, moral, espiritual e social, em condições de liberdade e de dignidade" ${ }^{\text {13 }}$, implica, para além da superação do tradicional modelo corretivo por meio de sevícias físicas, um resgate ontológico da própria paternidade/maternidade, como expressão de um amor abnegador pelos filhos que respeite suas individualidades.

\section{CONSIDERAÇÕES FINAIS}

A infância, em sentido amplo, pode ser entendida como uma construção cultural lastreada num tumultuado caminhar histórico cuja dinâmica sempre foi direcionada pela figura paterna.

Esta centralidade familiar do pater remonta às origens das primeiras legislações escritas, com especial destaque, no mundo ocidental, ao direito romano, o qual, mesmo com o advento do cristianismo, que propiciou uma relativa ressignificação da criança, continuou impactando as legislações subsequentes.

Paralelamente, a infância sempre foi vista como um movimento, uma transição, uma travessia que se iniciava com o nascimento e tinha como meta final a idade adulta e todas as responsabilidades sociais dela decorrentes.

A criança, portanto, não era um ser dotado de dignidade e personalidade próprias, mas um objeto de direito, um ser humano embrionário, em potencial, dependente da intervenção salvífica, moralizadora e resgatadora do bonus pater familiae.

No exercício deste ministério civilizatório, o pai, amparado nos mais amplos poderes concedidos pela tradição religiosa, política e cultural, e reafirmados pelos ordenamentos jurídicos ao longo dos séculos, lançou mão de castigos físicos e psicológicos, muitas vezes humilhantes, visando a educação da prole, ignorando as peculiaridades deste ser ainda em formação.

${ }^{13}$ Lei 8.069/90. Art. $3^{\circ}$. A criança e o adolescente gozam de todos os direitos fundamentais inerentes à pessoa humana, sem prejuízo da proteção integral de que trata esta Lei, assegurando-se-lhes, por lei ou por outros meios, todas as oportunidades e facilidades, a fim de lhes facultar o desenvolvimento físico, mental, moral, espiritual e social, em condições de liberdade e de dignidade. 
Esta prática não exclusiva dos "maus pais" foi replicada com os devidos ajustes nas mais diversas esferas e instituições públicas e privadas, seja nos reformatórios, abrigos de menores, hospitais psiquiátricos, institutos de educação, escolas de preservação, FEBEMs dentre outros similares, de tradição religiosa ou não.

Esta herança, portanto, encontra-se viva, presente e profundamente enraizada mesmo na sociedade secularizada do século XXI, refletindo, num certo sentido, nos índices de violência familiar contra crianças e adolescentes, que persistem em patamares intoleravelmente elevados.

Portanto, qualquer abordagem à violência infantil merece levar em consideração os diferentes padrões e expectativas em relação ao comportamento parental num determinado universo cultural, o qual, como visto, é resistente a mudanças legislativas isoladas, mesmo com a imposição de sanções aos pais ou responsáveis, sob pena de produzir-se uma indesejável e contraproducente polarização entre opressores (adultos) e oprimidos (crianças).

Sugere-se, assim, que o foco das políticas públicas procure afastar-se da simplista abordagem essencialmente dirigida às pessoas dos agressores e agredidos, eixo a partir da qual a maioria das medidas saneadoras da problemática são geralmente adotadas, para uma olhar holístico das causas maiores que levam genitores, muitas vezes bem intencionados, a agredirem imoderadamente seus filhos: miséria, distúrbios mentais, fragilização da autoridade parental, baixa instrução, negligência, violência geracional, abusos, inserção no mercado de trabalho, violência comunitária, drogas ilícitas, alcoolismo, enfraquecimento dos vínculos familiares, além da própria herança cultural, religiosa e familiar, conforme já pontuado.

Eis o enorme e complexo desafio da rede de proteção à infầncia e juventude do século XXI: preservar a criança em sua dignidade e personalidade, sem minar a autoridade parental, reconhecendo sua indispensabilidade para a formatação ética deste ser ainda em processo de construção.

\section{REFERÊNCIAS}

ALKIMIN, M. A. Uma reflexão em torno da violência doméstica contra a criança e o adolescente diante dos aspectos controvertidos e lacunosos da Lei 13.010, de 26.06.2014 (Lei da Palmada), Revista dos Tribunais 2016, RT VOL.964 (FEVEREIRO 2016) DOUTRINA DIREITO DA CRIANÇA E DO ADOLESCENTE. Disponível em: http://www.mpsp.mp.br/portal/page/portal/documentacao_e_divulgacao/doc_biblioteca/bibli_servicos_produtos/ bibli_boletim/bibli_bol_2006/RTrib_n.964.14.PDF. Acesso em 20 de abr. de 2021.

ALVES, J. C. M. Direito Romano, $18^{\mathrm{a}}$ ed. rev., Rio de Janeiro, Ed. Forense, 2018.

Revista de Direito de Família e Sucessão | e-ISSN: 2526-0227 | Encontro Virtual | v. 7 | n. 2 | p. $23-44$ | Jul/Dez. 2021. 
ARENDT, H. Sobre a Violência. Trad. André Duarte, 3a edição, Rio de Janeiro, Editora Relume Dumará, 2001.

ARIES, P. História Social da Criança e da Família, tradução Dora Flaksman, 2 a Ed, Rio de Janeiro, Editora Guanabara, 1986.

Assembleia Geral da ONU, Convenção Internacional sobre os Direitos da Criança, aprovada em 20 de novembro de 1989. Disponível em: https://www.unicef.org/brazil/convencao-sobre-os-direitos-da-crianca. Acesso em: 19 de jun. de 2021.

BAUMAN, Z. Modernidade Líquida, Tradução Plínio Dentizien, $1^{\text {a }}$ Ed. Editora Zahar, versão Kindle, Rio de Janeiro, 2001.

BÍBLIA SAGRADA. Traduzida em português por João Ferreira de Almeida. Revista e Atualizada no Brasil. $2^{\mathrm{a}}$ Ed., Sociedade Bíblica do Brasil, Barueri-SP, 2008.

BRASIL, Decreto 17.943-A, de 12-10-1927 (Código Melo Matos), 1927. Disponível em: https://www2.camara.leg.br/legin/fed/decret/1920-1929/decreto-17943-a-12-outubro-1927-501820publicacaooriginal-1-pe.html. Acesso em 20 de abr. de 2021.

BRASIL, Lei Federal n. 2040 de 28 de setembro de 1871 (Lei do Ventre Livre), 1971. Disponível em: http://www.planalto.gov.br/ccivil_03/leis/lim/lim2040.htm\#: :text=LIM2040\&text=Declara\%20de\%20condi\%C 3\%A7\%C3\%A3o\%20livre\%20os, de\%20escravos...... Acesso em 06 de jun. de 2021.

BRASIL, Lei federal $\mathbf{n}^{\mathbf{0}}$ 3.071, de $\mathbf{1}^{\mathbf{0}}$ de janeiro de 1916 (Código Civil), 1916. Disponível em: https://www2.camara.leg.br/legin/fed/lei/1910-1919/lei-3071-1-janeiro-1916-397989-publicacaooriginal-1pl.html\#: :text=Este $\% 20 \mathrm{C} \% \mathrm{C} 3 \% \mathrm{~B} 3$ digo $\% 20$ regula $\% 20$ os $\% 20$ direitos, bens $\% 20 \mathrm{e} \% 20 \% \mathrm{C} 3 \% \mathrm{~A} 0 \mathrm{~s} \% 20$ suas $\% 20 \mathrm{re}$ la $\% \mathrm{C} 3 \% \mathrm{~A} 7 \% \mathrm{C} 3 \%$ B5es.\&text $=$ Art.,-

2\%C2\%BA.\&text=Todo $\% 20$ homem $\% 20 \%$ C3\%A9\%20capaz $\% 20$ de $\% 20$ direitos $\% 20 \mathrm{e} \% 20$ obriga $\%$ C3 $\%$ A $7 \%$ C3 \%B 5 es $\% 20$ na $\% 20$ ordem $\% 20$ civil. Acesso em 20 de abr. de 2021.

BRASIL, Lei Federal n. 6.667, de 10 de outubro de 1979 (Código de Menores), 1979. Disponível em: https://www2.camara.leg.br/legin/fed/lei/1970-1979/lei-6697-10-outubro-1979-365840-publicacaooriginal-1pl.html. Acesso em 20 de abr. de 2021.

BRASIL, Lei Federal n. 8.069/90, de 13 de julho de 1990 (Estatuto da Criança e do Adolescente), 1990. Disponível em: http://www.planalto.gov.br/ccivil 03/leis/18069.htm. Acesso em 21 de jun. de 2021.

BRASIL, Lei Federal n. 13.010/2014 (Lei Menino Bernardo), 2014, Disponível em: http://www.planalto.gov.br/ccivil 03/ ato2011-2014/2014/lei/113010.htm. Acesso em 20 de abr. de 2021.

BRASIL, Ministério da Mulher, da Família e dos Direitos Humanos. Ouvidoria Nacional de Direitos Humanos (ONDH); Disque 100: Relatório violência contra crianças e adolescentes. Brasília, DF: ONDH; 2019. Disponível em: https://crianca.mppr.mp.br/arquivos/File/publi/mmfdh/disque 100 relatorio mmfdh2019.pdf; Acesso em: 06 de jun. de 2021.

BRASIL. Ministério da Saúde. DATASUS: Tecnologia da Informação a Serviço do SUS. Indicadores de saúde: causas externas. Brasília, DF: Ministério da Saúde; 2019. Disponível em:

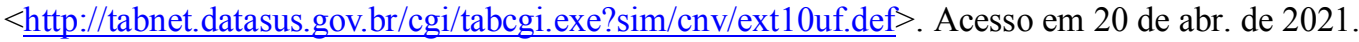

BURKE, E. Reflexões sobre a Revolução na França, tradução, apresentação e notas de José Miguel Nanni Soares, $1^{\text {a }}$ Ed., Editora Edipro, Versão Kindle, São Paulo, 2019.

CAVICHIOLI, R. S. Orientador: José Antônio Peres Gediel, Tese de Doutorado. Duas famílias, Duas Leis. Universidade Federal do Paraná, Setor de Ciências Jurídicas, Programa de Pós-graduação em Direito. Curitiba, 2019. 
https://www.prppg.ufpr.br/siga/visitante/trabalhoConclusaoWS?idpessoal=37426\&idprograma=40001016017P3 \&anobase $=2019$ \&idtc $=136$. Acesso em 20 de abr. de 2021.

BRASIL. Constituição da República Federativa do Brasil. Brasília, DF: Senado Federal: Centro Gráfico, 1988. Disponível em: http://www.planalto.gov.br/ccivil_03/constituicao/constituicao.htm. Acesso em 21 de jun. de 2021

COUlangeS, F. de. A Cidade Antiga (La Cité Antique), 1ª Ed., Editora Lebooks, Edição Kindle, 2020.

CUPIS, A. de. Os direitos da personalidade. Tradução de Afonso Celso Furtado Rezende - São Paulo: Quorum, 2008. Lisboa, 1961.

FERMENTÃo, C. Os Direitos da Personalidade como Direitos Essenciais e a Subjetividade do Direito. Revista Jurídica Cesumar. Publicada em 08/02/2007, v.06, n.1 (2006). Disponível em: https://periodicos.unicesumar.edu.br/index.php/revjuridica/article/view/313. Acesso em 20 de abr. de 2021.

FRANÇA, The Civil Code (Código Civil Francês). Publicado em 21 de março de 1804. Disponível em http://www.napoleon-series.org/research/government/c code.html. Acesso em 20 de abr. de 2021.

KANT, I. Sobre a Pedagogia. Trad. Francisco Cock Fontanella, 2a Ed., Piracicaba, Editora Unimep, 1999.

KRUG, E. G. et al. World Report on Violence and Health. Geneva, World Health Organization, 2002 , p. 59 e 60. Disponível em https://apps.who.int/iris/bitstream/handle/10665/42495/9241545615 eng.pdf?sequence=1. Acesso em 20 de abr. de 2021.

MACEDO, D. M.; LAWRENZ, P.; HOHENDORFF, J. V.; FREITAS, C.P. P.; KOLLER, S. H., HABIGZANG, L. F.. (2020). Characterization of Child Maltreatment Cases Identified in Health Services. Paidéia (Ribeirão Preto), 30, e 3018. Epub 08 de julho de 2020. Disponível em: < https://www.revistas.usp.br/paideia/article/view/173331>. Acesso em 20 de abr. de 2021.

MARTINS, C. B. de G. Maus tratos contra crianças e adolescentes. Rev. bras. enferm. (REBE) ano 2010, vol.63, n.4, pp.660-665. ISSN 0034-7167. https://doi.org/10.1590/S0034-71672010000400024. Disponível em https://www.scielo.br/pdf/reben/v63n4/24.pdf. Acesso em 20 de abr. de 2021.

MCLANAHAN, S. TACH, L. SCHNEIDER D. The Causal Effects of Father Absence; Annual Review of Sociology 2013 39:1, 399-427. Disponível em: https://www.annualreviews.org/doi/abs/10.1146/annurev-soc071312-145704. Acesso em 20 de abr. de 2021.

MEIRA, S.A. B. A Lei das XII Tábuas - Fonte do Direito Público e Privado, $3^{\mathrm{a}}$ ed. rev., Ed. Forense, Rio de Janeiro, 1972.

MORESCHI, M.T. Violência contra Crianças e Adolescentes: Análise de Cenários e Propostas de Políticas Públicas /Documento eletrônico - Brasília: Ministério dos Direitos Humanos, 2018, 494 p. Disponível em: https://www.gov.br/mdh/pt-br/centrais-de-conteudo/crianca-e-adolescente/violencia-contra-criancas-eadolescentes-analise-de-cenarios-e-propostas-de-politicas-publicas-2.pdf. Acesso em 20 de abr. de 2021.

NETO, E. F. Code Civil Francês: gênese e difusão de um modelo. Revista de Informação Legislativa da PUC/RS, Porto Alegre/RS, v. 1, p. 57-86, jan. 2013. Disponível em: https://repositorio.pucrs.br/dspace/handle/10923/11456. Acesso em: 25 mai. 2021.

NORONHA, C. S. Da instituição do Poder Familiar, em perspectiva histórica, moderna e pós moderna. Revista da Faculdade de Direito da UFRGS, n. 26, Porto Alegre/RS, 2006.

PAIVA, W. A. O legado dos jesuítas na educação brasileira. Educação em Revista UFMG. v. 31, n. 4, p. 201-222. Belo Horizonte/MG, 2015. Disponível em: 〈https://doi.org/10.1590/0102-4698136933〉. ISSN 19826621. Acesso em 26 de mai. de 2021

Revista de Direito de Família e Sucessão | e-ISSN: 2526-0227 | Encontro Virtual | v. 7 | n. 2 | p. 23 - 44 | Jul/Dez. 2021. 
PLATT, V. B. GUEDERT, J. M.; COELHO, E. B. S. Violência contra crianças e adolescentes: notificações e alerta em tempos de pandemia. Rev. Paulista de Pediatria. Abril de 2021. Disponível em: http://www.scielo.br/scielo.php?script=sci arttext\&pid=S0103-05822021000100434\&lng=en. Acesso em $20 \mathrm{de}$ abr. de 2021 .

RANGEL, A. W. G. Notas sobre os limites ao exercício do direito de correção paternal no Antigo Regime. Revista Direito FGV, São Paulo, v. 18, p. 615-634, jul. 2013. Quadrimestral. Disponível em: http://bibliotecadigital.fgv.br/ojs/index.php/revdireitogv/article/view/21446/20204. Acesso em: 16 jun. 2021.

SEGE, R. D.; SIEGEL, B.S.; Effective Discipline to Raise Healthy Children. Pediatrics: Official Journal of the American Academy of Pediatrics. EUA, 01 dez. 2018. Seção 6, p. 1. Disponível em: https://pediatrics.aappublications.org/content/142/6/e20183112/tab-article-info. Acesso em: 10 jun. 2021.

SOUZA, S. C. de. O Código Napoleão e sua Influência no Direito Brasileiro, Revista da EMERJ, v. 7, n. 26, $2004 . \quad$ Disponível em: https://www.emerj.tjrj.jus.br/revistaemerj_online/edicoes/revista26/revista26_36.pdf. Acesso em 20 de abr. de 2021.

SPOSATO, K. Elementos para uma teoria da responsabilidade penal de adolescentes. Tese de doutorado. Universidade Federal da Bahia, Salvador, 2011. Disponível em: https://repositorio.ufba.br/ri/bitstream/ri/15283/1/Tese\%20-\%20Karyna\%20Batista\%20Sposato.pdf. Acesso em: 06 de jun. de 2021.

ZAPATER, M. Direito da Criança e do Adolescente. $1^{\text {a }}$ ed. Editora Saraiva, São Paulo, 2019. 